\title{
Liberibacter crescens Is a Cultured Surrogate for Functional Genomics of Uncultured Pathogenic 'Candidatus Liberibacter' spp. and Is Naturally Competent for Transformation
}

\author{
M. Jain, ${ }^{1}$ L. Cai, ${ }^{1}$ L. A. Fleites,${ }^{1}$ A. Munoz-Bodnar, ${ }^{1}$ M. J. Davis, ${ }^{2}$ and D. W. Gabriel ${ }^{1, \dagger}$ \\ ${ }^{1}$ Department of Plant Pathology, University of Florida, Gainesville, FL 32611 \\ ${ }^{2}$ Department of Plant Pathology, Citrus Research and Education Center, University of Florida, Lake Alfred, FL 33850 \\ Accepted for publication 9 May 2019.
}

\begin{abstract}
'Candidatus Liberibacter' spp. are uncultured insect endosymbionts and phloem-limited bacterial plant pathogens associated with diseases ranging from severe to nearly asymptomatic. ' $\mathrm{Ca}$. L. asiaticus', causal agent of Huanglongbing or citrus "greening," and 'Ca. L. solanacearum', causal agent of potato zebra chip disease, respectively threaten citrus and potato production worldwide. Research on both pathogens has been stymied by the inability to culture these agents and to reinoculate into any host. Only a single isolate of a single species of Liberibacter, Liberibacter crescens, has been axenically cultured. L. crescens strain BT-1 is genetically tractable to standard molecular manipulation techniques and has been developed as a surrogate model for functional studies of genes, regulatory elements, promoters, and secreted effectors derived from the uncultured pathogenic Liberibacters. Detailed, step-by-step, and highly reproducible protocols for axenic culture, transformation, and targeted

gene knockouts of $L$. crescens are described. In the course of developing these protocols, we found that $L$. crescens is also naturally competent for direct uptake and homology-guided chromosomal integration of both linear and circular plasmid DNA. The efficiency of natural transformation was about an order of magnitude higher using circular plasmid DNA compared with linearized fragments. Natural transformation using a replicative plasmid was obtained at a rate of approximately 900 transformants per microgram of plasmid, whereas electroporation using the same plasmid resulted in $6 \times 10^{4}$ transformants. Homology-guided marker interruptions using either natural uptake or electroporation of nonreplicative plasmids yielded 10 to 12 transformation events per microgram of DNA, whereas similar interruptions using linear fragments via natural uptake yielded up to 34 transformation events per microgram of DNA.
\end{abstract}

'Candidatus Liberibacter' spp. are fastidious, uncultured, Gramnegative, and phloem-limited $\alpha$-proteobacteria (order Rhizobiales) that are emerging as a versatile group of plant pathogens capable of infecting a wide range of plant hosts. ' $C a$. L. asiaticus' causes Huanglongbing (HLB) or citrus "greening" disease and is arguably the single most devastating disease of citrus worldwide (Gabriel et al. 2019). HLB is also caused-to a much more limited extent-by ' $C a$. L. americanus' in Brazil and ' $C a$. L. africanus' in Africa. ' $\mathrm{Ca}$. L. asiaticus' is vectored and transmitted by the Asian citrus psyllid Diaphorina citri Kuwayama (Grafton-Cardwell et al. 2013). HLB is characterized by perturbed assimilate partitioning, progressive decline in productivity, and eventual death of infected citrus trees. ' $\mathrm{Ca}$. L. solanacearum' is vectored by the potato psyllid Bactericera cockerelli Sulc and causes zebra chip disease on potato (Lin et al. 2011). Zebra chip is marked by purplish discoloration and chlorosis of leaves, collapsed stolons, browning and necrotic flecking of vascular tissue in the tubers, and rapid death of infected potato plants. ' $\mathrm{Ca}$. L. solanacearum' is also capable of infecting several other Solanaceous and Apiaceous crops, causing psyllid

†Corresponding author: D. W. Gabriel; dgabr@ufl.edu

Current address of L. A. Fleites: Robert W. Holley Center for Agriculture and Health, U.S. Department of Agriculture Agricultural Research Service, Ithaca, NY 14853.

Funding: This work was supported by the Florida Citrus Research and Development Foundation (projects 108214 and 15-009) and the U.S. Department of Agriculture National Institute of Food and Agriculture Specialty Crops Research Initiative (grant 2016-70016-24844).

M. Jain and L. Cai contributed equally to this work.

The author(s) declare no conflict of interest.

(C) 2019 The American Phytopathological Society yellows in tomato, yellows decline, and vegetative disorders in carrots and celery (Monger and Jeffries 2018).

Only a single isolate of a single species of Liberibacter, Liberibacter crescens, has been cultured in vitro (Leonard et al. 2012). The wild-type L. crescens strain BT-1 (GenBank accession NC_019907.1) was originally isolated from the sap of Babaco mountain papaya (Carica stipulata $\times$ Carica pubescens) but it nevertheless has no known plant or insect host. Consistent failures in several laboratories to reinoculate BT-1 or derivatives into Babaco and other plants or insects have led to a consensus that BT-1 is both nonpathogenic and noninfectious. Although it is possible that some yet to be discovered strains of $L$. crescens might be parasitic if not pathogenic to plants, L. crescens is not listed as a pathogen by the U.S. Department of Agriculture Animal and Plant Health Inspection Service on its U.S. Regulated Plant Pest List. By contrast with cultured $L$. crescens BT-1 and derivatives, all pathogenic ' $C a$. Liberibacter' spp. are uncultured to date.

The sequenced ' $C a$. L. asiaticus' strain gxpsy (NC_020549.1; Duan et al. 2009), 'Ca. L. americanus' strain Sao Paulo (CP006604.1; Wulff et al. 2014), 'Ca. L. africanus' strain PTSAPSY (NZ_ CP004021.1; Lin et al. 2015), and 'Ca. L. solanacearum' strain ZC1 (NC_014774.1; Lin et al. 2011) all have highly reduced genome sizes of $\sim 1.2 \mathrm{Mb}$ compared with the slightly larger $1.5 \mathrm{Mb}$ of L. crescens BT- 1 and the $\sim 6.7 \mathrm{Mb}$ genome of the phylogenetically related Sinorhizobium meliloti (NC_003047.1). L. crescens BT-1 appears to have diverged earlier during evolution than the pathogenic 'Ca. Liberibacter' spp. (Nakabachi et al. 2013). Comparative genomics and metabolic pathway analyses of all Liberibacter genomes have revealed a trend for the reduction or complete absence of several biosynthetic pathways, metabolic enzymes, and secretion systems (Wulff et al. 2014).

Attempts to culture ' $\mathrm{Ca}$. L. asiaticus' in axenic media have resulted only in inconsistent, transient, and "low-titer" (estimated only by 
quantitative PCR) cocultures to date (Davis et al. 2008; Fujiwara et al. 2018; Merfa and De La Fuente 2019; Parker et al. 2014). The inability to culture pathogenic ' $\mathrm{Ca}$. Liberibacter' spp. or even to reinoculate transient cocultures into insect or plant hosts has severely restricted functional genomic analyses of suspected pathogenicity factors, molecular characterization of host-pathogen interactions, and subsequent development of chemical control methods for HLB and zebra chip. ' $C a$. L. asiaticus' genes that are differentially expressed in plant and insect hosts, and those involved in transcriptional regulation, major metabolic pathways, secretion and transportation systems, motility, and signal transduction, have all been predicted as potential virulence factors (Cong et al. 2012; Yan et al. 2013). Absent cultured pathogenic ' $C a$. Liberibacter' spp., the $\gamma$-proteobacterium Escherichia coli and the phylogenetically related $\alpha$-proteobacteria $S$. meliloti and L. crescens have primarily been used as surrogate gene expression hosts for specific functional analyses.

E. coli has proved useful in attempts to validate predicted leader peptides encoded by genes cloned from ' $\mathrm{Ca}$. L. asiaticus' and periplasmic localization of these proteins (Prasad et al. 2016), as well as outer membrane localization of ' $\mathrm{Ca}$. L. asiaticus' type V autotransporters (Hao et al. 2013). Even though all Liberibacters including $L$. crescens lack the T2SS (Fagen et al. 2014), only L. crescens has been used to demonstrate extracellular secretion of ' $C a$. L. asiaticus' enzymes and effectors. The prophage-encoded 'Ca. L. asiaticus' peroxidase (F489_gp15) was predicted using SecretomeP 2.0 (Bendtsen et al. 2005) to be noncanonically secreted. This prediction was experimentally confirmed by expression of the ' $\mathrm{Ca}$. L. asiaticus' peroxidase in L. crescens, whereas no such secretion was observed using the same clone expressed in E. coli (Jain et al. 2015). Similarly, the ' $C a$. L. asiaticus' peroxiredoxin gene (CLIBASIA_RS00445) was cloned and expressed in E. coli and functionally characterized as an active peroxiredoxin in vitro (Singh et al. 2017), but the enzyme was not reported as being secreted or having any pathogenicity function. However, nonclassical extracellular secretion of ' $\mathrm{Ca}$. L. asiaticus' peroxiredoxin was predicted using SecretomeP 2.0 and subsequently demonstrated by expression in L. crescens (Jain et al. 2018). Additional characterization of the gene expressed in planta confirmed its likely role in ' $\mathrm{Ca}$. L. asiaticus' pathogenesis (Jain et al. 2018, 2019b). The use of L. crescens to demonstrate extracellular secretion combined with transient expression assays in planta can effectively be used to identify potential ' $C a$. L. asiaticus' and ' $\mathrm{Ca}$. L. solanacearum' pathogenicity effectors.

S. meliloti has also been used for investigating ' $\mathrm{Ca}$. L. asiaticus' regulatory genes. For example, LdtR is a multidrug resistance regulator (MarR family transcriptional activator) of both $l d t R$ and the immediately downstream $l d t P$ (encoding L,D-transpeptidase) that are implicated in osmotic stress tolerance in S. meliloti (Pagliai et al. 2014). ' $C a$. L. asiaticus' also encodes $l d t R$ and $l d t P$ with similar gene organization, and small molecule-mediated inhibition of ' $C a$. L. asiaticus' LdtR (CLIBASIA_RS01145) appeared to reduce ' $C a$. L. asiaticus' titer in planta (Pagliai et al. 2014), possibly owing to a role of ' $C a$. L. asiaticus' $l d t P$ (CLIBASIA_RS01140) in preserving ' $\mathrm{C} a$. L. asiaticus' envelope and lipid A structure and hence osmotic tolerance, particularly in the sucrose-rich citrus phloem environment (Coyle et al. 2018).

' $C a$. L. asiaticus' LdtP was found to express unexpected esterase activity that resulted in altered $E$. coli lipid A structure (Coyle et al. 2018). The E. coli genome encodes the entire nine-enzyme Raetz pathway, resulting in six hydrophobic acyl chains that anchor lipid A in the bacterial outer membrane (Emiola et al. 2015). By contrast, L. crescens lacks the final Raetz pathway enzyme, LpxM (lauroylKdo2-lipid IVA myristoyltransferase), predictably resulting in penta-acylated lipid A. More importantly, all pathogenic (and uncultured) ' $C a$. Liberibacter' spp. also lack LpxL (Kdo2-lipid IVA lauroyltransferase), likely resulting in a tetra-acylated lipid A moiety. Arguably, L. crescens seems to be a better choice for functional studies of lipid A genes and structure determination.
L. crescens has been notoriously difficult to culture, and even thought to be recalcitrant to standard genome editing tools (Coyle et al. 2018). However, incremental improvements in media, culture conditions, and molecular techniques have yielded a very practical and reproducible toolkit for making $L$. crescens genetically tractable. The genome content of $L$. crescens is highly similar to and syntenic with the pathogenic ' $\mathrm{Ca}$. Liberibacter' spp. (Nakabachi et al. 2013). $L$. crescens is clearly the best available surrogate system for functional evaluation of ' $C a$. L. asiaticus' and ' $C a$. L. solanacearum' promoter elements, genes affecting ' $\mathrm{Ca}$. Liberibacter' spp. membranes, cell structure, and secretion. When combined with transient expression systems in plant hosts, responses to suspected plant effectors can be confirmed. L. crescens was shown to colonize the greater wax moth (Galleria mellonella), a model insect host (Munoz-Bodnar et al. 2019), raising the possibility of evaluating responses to suspected insect effectors. We provide detailed and highly reproducible protocols for growth, storage, genetic transformation, and site-directed mutagenesis in L. crescens strain BT-1. We also demonstrate that $L$. crescens BT- 1 is naturally competent for uptake of both linear and circular plasmid DNA and chromosomal integration via homologous recombination, thereby eliminating the need for electroporation.

\section{MATERIALS AND METHODS}

Culture conditions for $L$. crescens strain BT-1. Growth of L. crescens BT-1 cells (ATCC BAA-2481) was adequately supported on Basal Medium 7 (BM7) consisting of $2 \mathrm{~g}$ of $\alpha$-ketoglutaric acid, $10 \mathrm{~g}$ of $\mathrm{N}$-(2-acetamido)-2-aminoethanesulfonic acid (ACES) buffer, and $3.75 \mathrm{~g}$ of $\mathrm{KOH}$ in $550 \mathrm{ml}$ of water, $\mathrm{pH} 6.9$, followed by the addition of $300 \mathrm{ml}$ of filter-sterilized fetal bovine serum (HyClone Laboratories, Logan, UT) and $300 \mathrm{ml}$ of modified Grace's insect culture medium (TNM-FH; HyClone Laboratories; Hink 1970) with gentle shaking at $150 \mathrm{rpm}$ at $28^{\circ} \mathrm{C}$. For long term storage, BT-1 was maintained in BM7 plus $25 \%$ glycerol ( vol/vol) and stored frozen at $-80^{\circ} \mathrm{C}$. From glycerol stocks, cultures were initiated as streaks on BM7 medium solidified with $1.5 \%$ (wt/vol) agar (Difco Agar; BD Diagnostics, VWR, Radnor, PA). From streaks taken from freezer stocks, it usually took between 5 and 6 weeks to isolate single-cell BT- 1 colonies for use in liquid cultures or restreaking on solid plates. A marked improvement to achieve higher titers and longer cell survival was to modify BM7 by doubling the ACES buffer (i.e., adding $20 \mathrm{~g} /$ liter of medium), termed BM7A medium.

Initially BT-1 colonies on BM7 appeared luminous and transparent, gradually maturing over a period of 10 to 12 days to a dull white appearance. Mature white colonies quickly lost viability within 10 to 12 additional days and had to be transferred to fresh medium during this time. This time was not extendable by refrigeration of plates. Growth of a single mature colony removed from a freshly streaked plate and inoculated in liquid BM7 medium yielded an $\mathrm{OD}_{600}$ of 0.65 in 5 days at $28^{\circ} \mathrm{C}$, corresponding to $\sim 10^{7}$ $\mathrm{CFU} / \mathrm{ml}$. BT-1 cultures were routinely maintained by transferring $100 \mu \mathrm{l}$ of culture to $2 \mathrm{ml}$ of fresh BM7 or BM7A medium every 5 to 7 days, respectively. L. crescens BT-1 stocks and cultures were routinely examined by PCR (Table 1) to authenticate the purity of cultures.

Genomic DNA extraction, PCR amplification, and cloning. Genomic DNA from L. crescens cells was extracted using the GenElute Bacterial Genomic DNA kit (Sigma-Aldrich, St. Louis, MO) following the manufacturer's recommendations. PCR reactions were performed using AccuPrime Taq DNA Polymerase High Fidelity (Invitrogen, Carlsbad, CA) and the amplification products were cloned into pCR2.1TOPO (Invitrogen) and transformed into E. coli TOP10 (Invitrogen) cells using the manufacturer's protocol. The plasmids were verified for sequence fidelity.

Preparation of electrocompetent cells of $L$. crescens strain BT-1. L. crescens BT-1 cells were transformed by 
electroporation partly following a protocol of Guilhabert and Kirkpatrick (2003) useful for Xylella fastidiosa, but with several important modifications. A 2-ml starter culture of BT-1 cells was grown at $28^{\circ} \mathrm{C}$ with orbital shaking in a glass tube (for maximum visibility) at $150 \mathrm{rpm}$ for 5 days. The entire culture was diluted with fresh BM7 or BM7A medium to a final volume of $10 \mathrm{ml}$ and placed in a $220-\mathrm{ml}$ Erlenmeyer flask. The cells were grown at $28^{\circ} \mathrm{C}$ with orbital shaking for 2 days, an additional $40 \mathrm{ml}$ of BM7 or BM7A was added, and growth continued for 3 more days. The 5-day-old BT-1 cell culture $\left(50 \mathrm{ml}, \mathrm{OD}_{600}=0.5\right)$ was chilled on ice for $30 \mathrm{~min}$, centrifuged at $4,000 \mathrm{rpm}$ at $4{ }^{\circ} \mathrm{C}$, and washed once in $50 \mathrm{ml}$ and once in $20 \mathrm{ml}$ of ice-cold sterile distilled water. The cell pellet was finally washed in $20 \mathrm{ml}$ of ice-cold $10 \%$ glycerol (vol/vol) and then resuspended in $1 \mathrm{ml}$ of ice-cold $10 \%$ glycerol. Forty-microliter aliquots of competent cells were flash-frozen in liquid nitrogen and stored at $-80^{\circ} \mathrm{C}$.

Transformation of $L$ crescens strain BT-1 by electroporation. For electroporation, an aliquot of competent cells was thawed on ice and gently mixed with $\sim 5 \mu \mathrm{l}(=1 \mu \mathrm{g})$ of plasmid DNA. The mixture of competent cells and DNA was transferred to a $1-\mathrm{mm}$ cuvette prechilled at $-20^{\circ} \mathrm{C}$ and electroporated at $1,800 \mathrm{~V}$, yielding a time constant in the range from $\sim 5.6$ to $6.2 \mathrm{~ms}$ (Eppendorf Electroporator 2510; VWR). Any transformation mixtures yielding a time constant below $5.6 \mathrm{~ms}$ were discarded. The electroporated cells were immediately recovered in $900 \mu \mathrm{l}$ of BM7 or BM7A broth without antibiotics and transferred to 5-ml sterile tubes. The transformed cells were allowed to recover for $16 \mathrm{~h}$ in liquid BM7 or BM7A medium without antibiotics with gentle shaking at $28^{\circ} \mathrm{C}$ at $150 \mathrm{rpm}$ and finally were plated on $30 \mathrm{ml}$ of BM7 or BM7A medium solidified with $1.5 \%$ (wt/vol) agar, with antibiotic selection.

Site-directed mutagenesis in L. crescens strain BT-1. L. crescens strain BT-1 was marked with a kanamycin $(\mathrm{Kn})$ resistance gene via marker interruption of a nonessential target locus, lcrRIP (type I restriction endonuclease subunit R; B488_ RS03405) in the chromosome, following the strategy outlined in Castañeda et al. (2005). A partial (769 bp) DNA fragment internal to the $l c r R I P$ coding region was amplified using primers MJ01 and MJ02 (Table 1) and the amplicon was cloned into nonreplicative plasmid (in L. crescens) pCR2.1-TOPO (pUC ori, $\mathrm{Kn}^{\mathrm{R}}$; Invitrogen). The resulting suicide plasmid pMJ01 (Table 2) was transformed into $L$. crescens strain BT-1 by electroporation.
Natural transformation of $L$. crescens strain BT-1. A $40-\mu \mathrm{l}$ aliquot of electrocompetent BT-1 cells was mixed gently with $1 \mu \mathrm{g}$ of linear or closed circular plasmid DNA (either replicative or not) and $50 \mu \mathrm{l}$ of chitin (1 mM, C-3387; Sigma-Aldrich) or xanthan gum $(0.5 \% \mathrm{wt} / \mathrm{vol}$ in water, G-1253; Sigma-Aldrich). The transformation mix was resuspended in $850 \mu$ l of liquid BM7A medium, incubated with gentle shaking at $28^{\circ} \mathrm{C}$ at $150 \mathrm{rpm}$ for $48 \mathrm{~h}$, and finally plated on selective BM7A medium containing gentamycin (Gm; $2.0 \mathrm{mg} / \mathrm{liter})$.

Natural uptake and transformation of $L$. crescens strain BT-1 was also demonstrated by interruption of the target locus $l c r R I P$ using either linear or circular "suicide" (narrow host range, E. coli replicon) plasmid DNA. The lcrRIP internal fragment $(2 \mathrm{~kb})$ was amplified with the primer pair CLL02F and CLL05R and cloned into pCR2.1-TOPO (Invitrogen) to yield the suicide plasmid pCLL02 (KnR; Table 2). The Gm resistance gene (aminoglycoside3-O-acetyltransferase I gene, aacC1; 834 bp) was PCR amplified from pUFR071 (De Feyter and Gabriel 1991) using the primers CLL11F and CLL11R and ligated within the lcrRIP fragment using an internal $S a l I$ restriction site to yield suicide plasmid pCLL04 $\left(\mathrm{Kn}^{\mathrm{R}}\right.$ and $\left.\mathrm{Gm}^{\mathrm{R}}\right)$. Both pCLL04 $(6.765 \mathrm{~kb})$ and the BamHI/SmaI-digested linear insert $(2.834 \mathrm{~kb})$ were used for BT-1 transformation.

\section{RESULTS}

Optimized culture conditions for $L$. crescens strain BT-1. Liquid cultures of $L$. crescens BT-1 grown for longer than 5 days in liquid medium often failed to grow upon transfer to fresh BM7 medium, despite measurably increasing $\mathrm{OD}_{600}$ after 5 days. The consistent increase in $\mathrm{OD}_{600}$ observed for 8 days after BT-1 growth in BM7 medium was not correlated with bacterial viability (Fig. 1A). In a conventional spot cell count assay, BT-1 viability (in $\mathrm{CFU} / \mathrm{ml}$ ) was significantly reduced after 6 days of culture in BM7, and the cells were completely nonviable by day 8 (Fig. 1B). However, in BM7A medium containing $2 \times$ ACES buffer ( $20 \mathrm{~g} /$ liter), liquid cultures of $L$. crescens BT-1 were reliably maintained and transferred to fresh medium for up to 12 days. Higher concentrations (up to $4 \times$ ) of ACES or substituting 2-( $N$-morpholino) ethanesulfonic acid in BM7 medium decreased the viability of L. crescens (data not shown). BT-1 cells in liquid culture also lost viability rapidly (within days) when stored at $4^{\circ} \mathrm{C}$.

TABLE 1. Primers used in this study

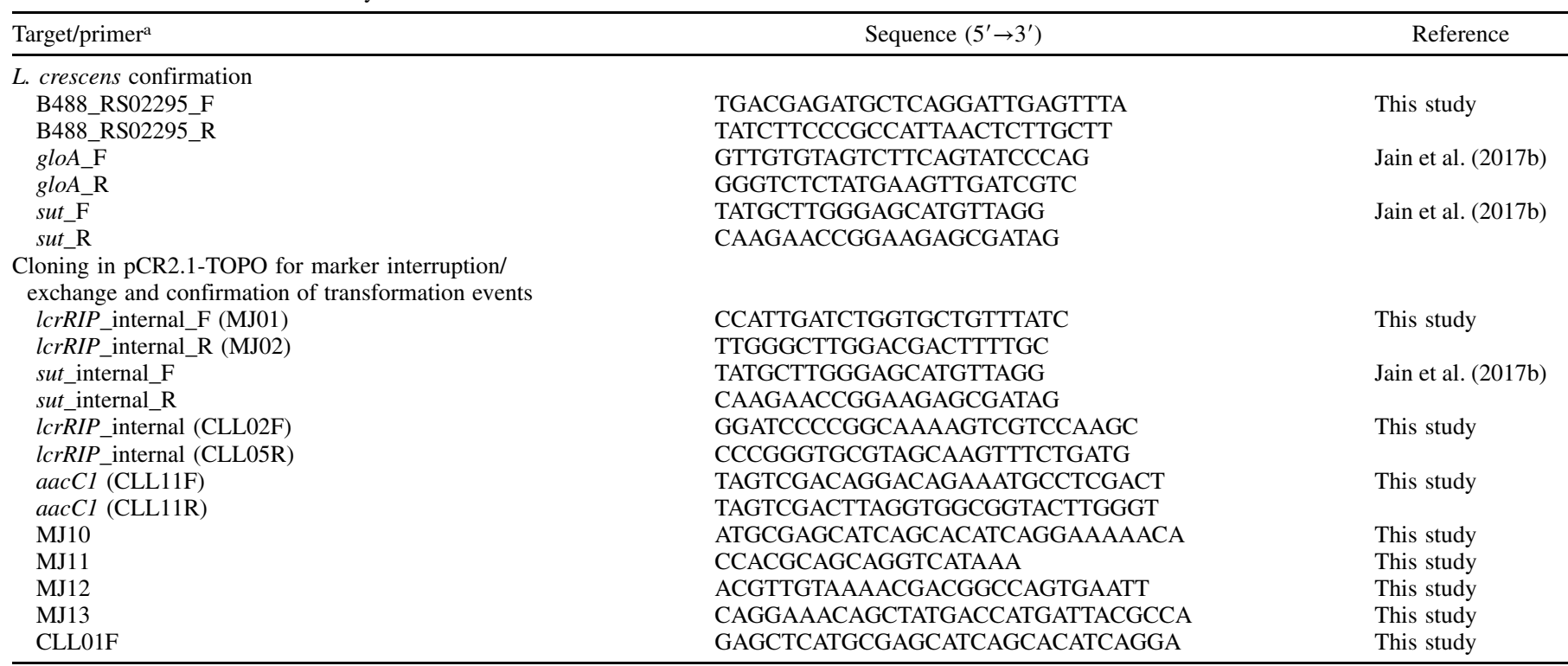

${ }^{\mathrm{a}} \mathrm{F}=$ forward, $\mathrm{R}=$ reverse, $g l o A=$ glyoxalase I (B488_RS02175), sut = sugar transporter (B488_RS00965), lcrRIP = putative restriction subunit R (B488_ RS03405), and $a a c C l=$ aminoglycoside-3-O-acetyltransferase I gene (gentamycin acetyltransferase). 
Compatible replicative vectors and useful antibiotics for transformation of $L$. crescens strain BT-1. While preparing electrocompetent cells, it was essential to increase the 2-ml starter culture volume in a stepwise manner, increasing to $10 \mathrm{ml}$ and then to $50 \mathrm{ml}$ to obtain reproducible growth $\left(\mathrm{OD}_{600}=0.5\right)$ of competent BT-1 cells in 5 days. The transformation competence of prepared cells was compromised significantly if the cells were harvested at $\mathrm{OD}_{600}>0.5$. Given the long incubation time needed for recovering primary transformation events, it was critical that the transformation mix was plated on at least $30 \mathrm{ml}$ of selective medium to avoid desiccation.

To determine whether $L$. crescens BT- 1 might be tractable for functional genomics studies, the minimum inhibitory concentrations of several antibiotics commonly used for plasmid selection were determined. BT-1 was quite sensitive to chloramphenicol (Cm; $<4 \mathrm{mg} / \mathrm{liter}), \mathrm{Gm}$ ( $<1 \mathrm{mg} / \mathrm{liter}), \mathrm{Kn}(<2.5 \mathrm{mg} / \mathrm{liter})$, and tetracycline $(<0.3 \mathrm{mg} /$ liter $)$. Wide-host-range shuttle plasmids pUFJ05 (Bordetella replicon, Gm²; Reddy et al. 2007) and pUFR071 (RepW, GmR , and Cm²; De Feyter and Gabriel 1991) (Table 2) were transformed by electroporation at high frequencies into BT-1. The transformation frequencies were estimated to be $3 \times 10^{3}$ transformants/ $\mu \mathrm{g}$ of DNA for pUFJ05 and $\sim 20 \times$ greater for pUFR071, when selected either on BM7 with Gm (2.0 mg/liter) or $\mathrm{Cm}(2.5 \mathrm{mg} / \mathrm{liter})$. The recovery of primary transformation events was relatively slow and typically yielded colonies only after 5 to 6 weeks of incubation. In our experience, $\mathrm{Cm}$ selection delayed recovery of primary transformants by approximately 2 additional weeks and Gm was the preferred antibiotic for plasmids pUFJ05 and pUFR071 that carry both $\mathrm{Gm}^{\mathrm{R}}$ and $\mathrm{Cm}^{\mathrm{R}}$ selectable markers. The primary transformed colonies always appeared transparent and luminous in the beginning and required an additional 2 weeks for maturation. It was extremely important to streak only the mature, opaque dull white colonies on fresh plates to preserve their viability. Even for wild-type BT-1 grown on agar media, the initially transparent and luminous colonies failed to grow upon restreaking. After restreaking and growth on selective solid medium, liquid BM7 cultures were initiated with appropriate antibiotic selection from mature and opaque dull white colonies. The transformed BT-1 strains were routinely maintained in liquid BM7A medium as described above following a 5- to 7-day subculture schedule.
High transformation efficiencies were routinely achieved with several wide-host-range shuttle vectors, including pUFR047 (RepW; De Feyter et al. 1993), pBBR1MCS-5 (Bordetella replicon; Kovach et al. 1995), and pUFZ075 (RepW) for constitutive expression of green florescent protein (GFP) (Zhang et al. 2009). BT-1 cells transformed with pUFR071 showed only a marginal loss of the plasmid when grown for $>70$ generations in the absence of $\mathrm{Gm}(2.0 \mathrm{mg} / \mathrm{liter})$ selection (Fig. 2A). The results are in line with the expected stability of RepW origin in the presence of stabilizing partition locus parA (De Feyter et al. 1990). Plasmid extracted from BT-1 cells transformed with pUFR071 was retransformed into E. coli TOP10 cells and appeared from restriction analysis to be unchanged (Fig. 2B). L. crescens BT-1 cells were also highly amenable to cotransformation as well as sequential transformation using a combination of compatible plasmids and appropriate selective antibiotics (pUFR071 and pUFJ05, $\mathrm{Gm}^{\mathrm{R}}$ and $\mathrm{Kn}^{\mathrm{R}}$; Munoz-Bodnar et al. 2018).

Site-directed mutagenesis for $L$. crescens strain BT-1 via marker interruption. For site-directed mutagenesis, pCR2.1TOPO $\left(\mathrm{Kn}^{\mathrm{R}}\right)$ was used in these studies but any "suicide" vector (capable only of replication in E. coli) could likely be used. Marker interruption of the nonessential target locus lcrRIP (B488_ RS03405) in the chromosome was achieved, following the strategy outlined in Castañeda et al. (2005). Electroporation of BT-1 cells with pMJ01, carrying a PCR fragment amplified from the internal coding region of $l c r R I P$ cloned in pCR2.1-TOPO, resulted in a single homologous recombination event interrupting the target gene lcrRIP and integrating the vector between two incomplete copies of the target gene (Fig. 3A). In a typical transformation experiment for marker interruption at this or any one of several mutated loci (Table 2 and refer below), $\sim 10$ transformants/ $\mu \mathrm{g}$ of plasmid DNA were obtained in 10 weeks on antibiotic selection (Kn, $4.5 \mathrm{mg} / \mathrm{liter})$. Three independently obtained $\mathrm{Kn}^{\mathrm{R}}$ colonies (lcrRIP::pMJ01) were analyzed by PCR to confirm interruption of the target gene and integration of the plasmid backbone (Fig. 3B).

Natural transformation, site-directed marker interruption, and marker exchange in $L$. crescens strain BT-1. The pathogenic ' $\mathrm{Ca}$. Liberibacter' genomes are predicted to possess all structural genes required for assembly of type IV pilus (T4P)

TABLE 2. Bacterial strains and plasmids used in this study

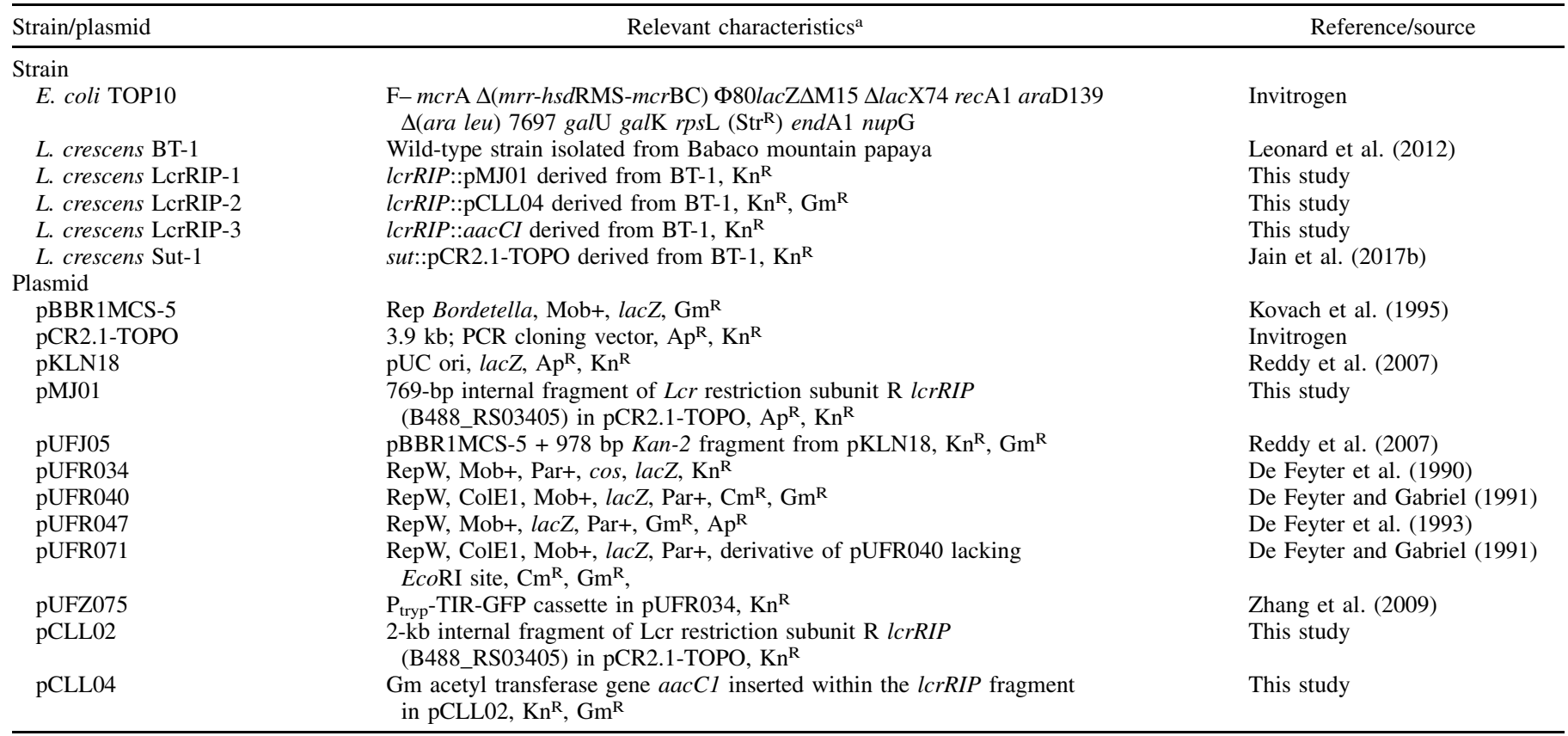

\footnotetext{
${ }^{a}$ Str $=$ streptomycin, lcrRIP = putative restriction subunit R (B488_RS03405), Kn = kanamycin, Gm = gentamycin, sut = sugar transporter $\left(\mathrm{B} 488 \_\mathrm{RS} 00965\right), \mathrm{Ap}=$ ampicillin, $L c r=$ Liberibacter crescens, Kan = kanamycin, $\mathrm{Cm}=$ chloramphenicol, GFP $=$ green fluorescent protein, and $a a c C 1=$ aminoglycoside-3-Oacetyltransferase I gene (gentamycin acetyltransferase)
} 
(Andrade and Wang 2019). In addition to predicted T4P genes, the L. crescens genome also encodes the Vibrio cholerae homologs (Seitz and Blokesch 2014) needed for natural DNA uptake and transformation: comF (B488_RS05095), comEA (B488_ RS00175), and comEC (B488_RS05330) for DNA uptake; $s s b \bar{B}$ (B488_RS01885) and dprA (B488_RS04595) for DNA protection; and recA (B488_RS02195) for recombination. To determine whether $L$. crescens could naturally take up exogenously supplied DNA, the 9.4-kb shuttle vector pUFR071 (used for electroporation) and chitin or xanthan gum were mixed with thawed electroporation competent $L$. crescens cells, but this time without the use of electroporation. The transformation mix was incubated for $48 \mathrm{~h}$ with $850 \mu \mathrm{l}$ of liquid BM7A medium, resulting in $\sim 900$ transformation events. By comparison, $6 \times 10^{4}$ transformed L. crescens cells were obtained via electroporation of the same plasmid with similarly prepared competent cells. Natural transformation was dependent on the addition of chitin or xanthan gum to the $L$. crescens cells/DNA transformation mix. Cells not washed repeatedly with water and $10 \%$ glycerol (as described in the Materials and Methods) did not appear competent for natural transformation.

To determine whether $L$. crescens could integrate naturally acquired exogenously supplied DNA into its genome, marker interruption of the nonessential target locus $l c r R I P$ was performed. Both linear and circular plasmid vector DNA carrying an internal
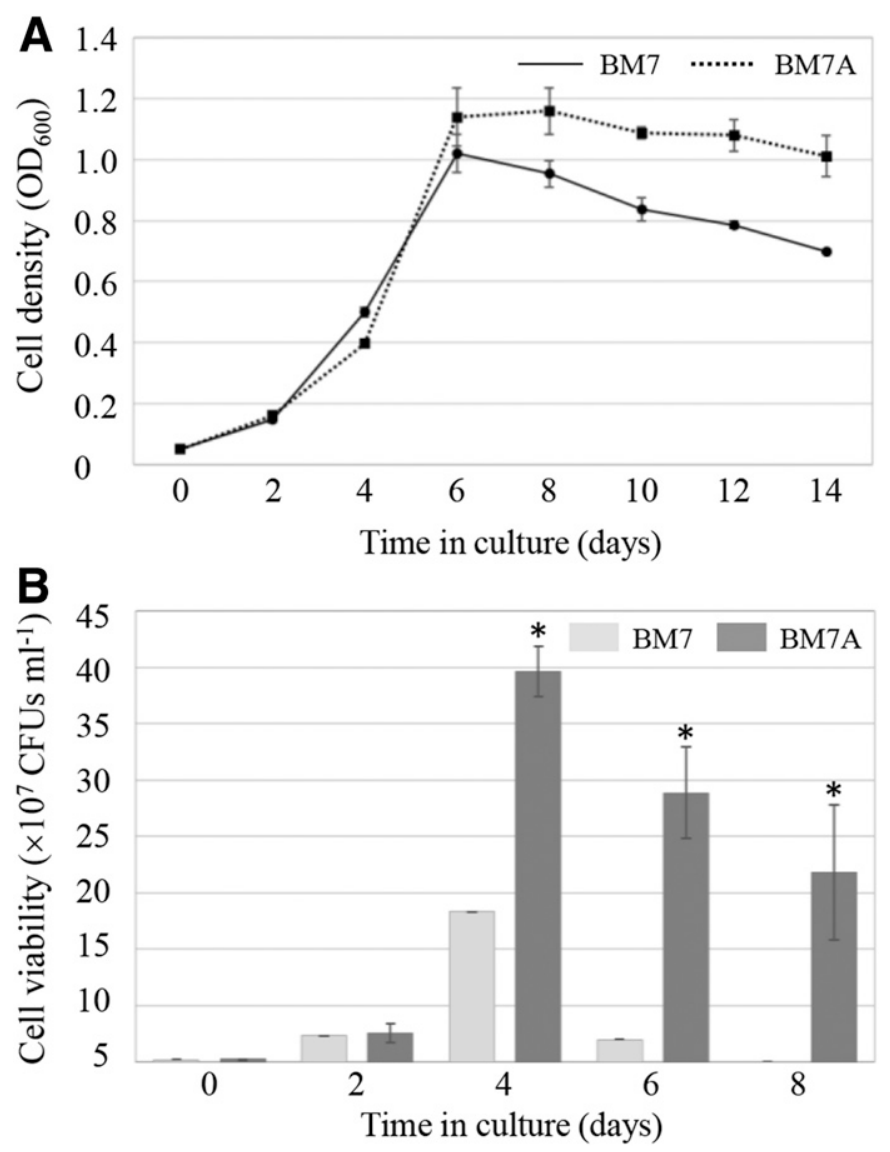

Fig. 1. Effect of $N$-(2-acetamido)-2-aminoethanesulfonic acid (ACES) buffer concentration on viability of Liberibacter crescens strain BT-1 cells in culture. Growth of $L$. crescens cells in Basal Medium 7 (BM7) or BM7A (containing 10 or $20 \mathrm{~g} /$ liter of ACES, respectively) was monitored for A, an increase in absorbance $\left(\mathrm{OD}_{600}\right)$ and $\mathbf{B}$, cell viability (in $\left.\mathrm{CFU} / \mathrm{ml}\right)$. For cell viability assays, $100 \mu \mathrm{l}$ of $L$. crescens cells was withdrawn at the indicated time points, serially diluted, and enumerated for viable cell counts. The data represent means \pm SD of three experiments with three replicates each. Asterisks indicate significant differences between the treatment means as determined by the Student's $t$ test $(P<0.05)$. fragment(s) of lcrRIP plus the Gm acetyltransferase (aacCl) were used for natural uptake and homology-guided integration by L. crescens cells. The schematic design of pCLL04 used for demonstration of homology-directed integration and marker interruption of $l c r R I P$ is illustrated in Figure 4A. Nonreplicative plasmid pCLL04 reliably yielded $\sim 10$ to 12 transformation events. Similar transformation efficiencies were routinely obtained with electroporated circular suicide plasmids for insertional mutagenesis of target loci (Jain et al. 2017b; Naranjo et al. 2019). A single homologous recombination event within the target locus lcrRIP resulted in integration of the vector backbone carrying the Kn resistance gene in between two incomplete copies of the target while also knocking in the $\mathrm{Gm}$ resistance gene in the recipient strain lcrRIP::pCLL04 (Fig. 4C). L. crescens transformants (lcrRIP:: pCLL04) were also verified for their ability to grow on either of the two antibiotics ( $\mathrm{Kn}$ and $\mathrm{Gm})$.

Natural transformation was also achieved by providing homologous linear DNA fragments via two homologous recombination events (marker exchange). For example, BamHI/SmaI digestion of pCLL04 released a 2.834-kb insert with the Gm resistance gene ( a acCI) flanked by 1-kb regions homologous with $l c r R I P$ on each side (Fig. 4B). This fragment was gel purified and incubated with
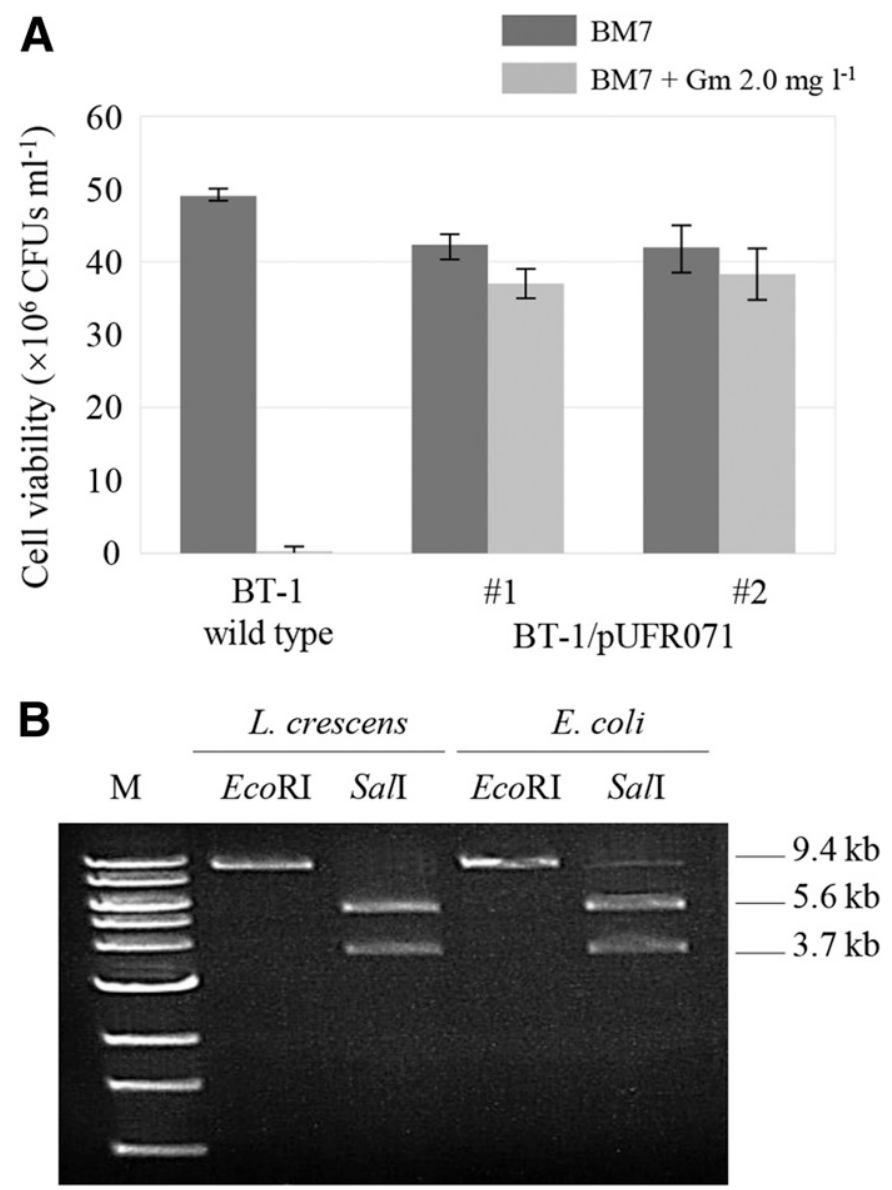

Fig. 2. A, Growth of Liberibacter crescens strain BT-1 wild-type and pUFR071-transformed cells on Basal Medium 7 (BM7) with and without antibiotic selection. Cell density (in CFU/ml) was determined on plain and selective (gentamycin $[\mathrm{Gm}], 2.0 \mathrm{mg} / \mathrm{ml}$ ) BM7. Two independently transformed colonies, numbers 1 and 2, were grown for 70 generations in BM7 liquid medium without antibiotic selection, serially diluted, and plated on plain and selective BM7 plates $(n=3)$. B, Diagnostic agarose gel $(0.8 \%)$ electrophoresis of EcoRI/SalI-digested plasmid DNA extracted from pUFR071transformed L. crescens BT-1 and Escherichia coli Top10 cells. pUFR071 was extracted from transformed BT-1 cells and retransformed in E. coli. A single 9.4-kb EcoRI fragment and two 5.6- and 3.7-kb SalI fragments were visualized by ethidium bromide staining (M, 1-kb DNA ladder). 
electrocompetent L. crescens cells (plus either chitin or xanthan gum) to yield three to four transformation events per microgram of DNA. Integration of aacCI within the target locus (lcrRIP::aacCI) was mediated through two recombination events and was confirmed as a marker exchange product by PCR analysis (Fig. 4C). The efficiency of marker exchange appeared dependent on the length of the flanking homologous regions. Homologous flanking regions of $250,500,750$, and $1,000 \mathrm{bp}$ each were evaluated, and the flanking region length of $750 \mathrm{bp}$ on each side was optimal, yielding $\sim 34$ transformation events for marker exchange of $l c r R I P$.

\section{DISCUSSION}

Extensive genome reductive evolution has rendered the plantpathogenic and insect-endosymbiotic ' $C a$. Liberibacter' spp. strictly dependent on intracellular lifestyles (Hartung et al. 2011; Jain et al. 2017b). Lack of axenic culture methods has severely restricted functional genomic analyses and subsequent development of chemical control methods for pathogenic ' $\mathrm{Ca}$. Liberibacter' spp. Despite high genomic similarity and syntenic context (Nakabachi et al. 2013), the core Liberibacter genomes share only 658 genes and most of the species-specific genes encode proteins of unknown function (Fagen et al. 2014; Wulff et al. 2014). Bioinformatic analysis also revealed that $37 \%$ of the functionally annotated genes in the $L$. crescens genome are species specific compared with $17 \%$ in ' $\mathrm{Ca}$. L. asiaticus' and $20 \%$ in ' $\mathrm{Ca}$. L. solanacearum' (Wulff et al. 2014). As described below, molecular characterization of some of the functionally annotated ' $\mathrm{Ca}$. L. asiaticus' genes using L. crescens as a surrogate host has already provided valuable insights into both the bacterial requirements for free-living growth in axenic culture and host-pathogen interactions.

L. crescens was first used for functional genomics analyses of ' $C a$. L. asiaticus' genes to investigate the repression of a strong
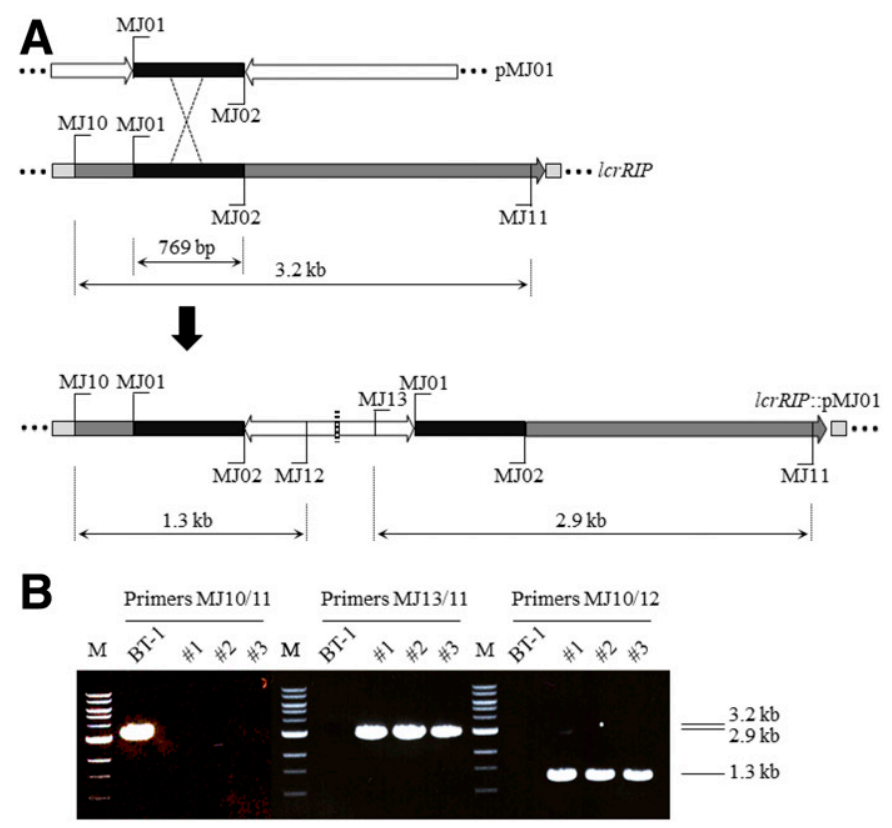

Fig. 3. A, Schematic representation of a single homologous recombination event leading to duplication of the cloned homology region (filled black box) and integration of suicide vector pMJ01 (empty white box) in between two incomplete copies of the target locus (lcrRIP) in Liberibacter crescens BT-1 cells (lcrRIP::pMJ01). B, Agarose gel (0.8\%) electrophoresis showing the indicated PCR products obtained using primer pairs MJ10/11 for amplification of the target regions in wild-type L. crescens BT-1, and MJ13/11 and MJ10/12 for amplification of the vector-interrupted target regions in three independently transformed lcrRIP::pMJ01 strains. Directional positions of different primers and sizes of the PCR-amplified products are indicated in A. Lanes: $\mathrm{M}=1-\mathrm{kb}$ DNA ladder, and \#1, \#2, and \#3 = three independently transformed lcrRIP::pMJ01 clones. constitutive 'Ca. L. asiaticus' phage holin (F488_gp16) promoter (Fleites et al. 2014). A small protein encoded by the genus Wolbachia (a primary endosymbiont of $D$. citri) was found to permeate $L$. crescens cells, bind to the promoter, and repress holin expression, thereby providing the first example of protein-mediated interspecies bacterial communication not related to quorum sensing (Jain et al. 2017a). Two ' $C a$. L. asiaticus' plant effectors, one a prophage-encoded peroxidase and the other a chromosomally encoded peroxiredoxin, were also functionally characterized using L. crescens as a surrogate host to confirm extracellular secretion and enzymatic activity; transient expression assays were then used to confirm suppression of both reactive oxygen species-mediated systemic and localized defense signaling cascades in planta (Jain et al. 2015, 2018, 2019b).

Systemic, circulative, and propagative colonization of the psyllid hosts by ' $C a$. L. asiaticus' and ' $C a$. L. solanacearum' depends on attachment to the midgut cells, traversing through it and biofilm formation on the outer midgut surface and likely involving active motility within the hemolymph. All ' $C a$. L. asiaticus' T4P genes examined were upregulated in the psyllid host by comparison with the citrus host (Andrade and Wang 2019). Despite numerous observations of ' $\mathrm{Ca}$. L. asiaticus' in citrus and psyllids, neither flagella nor pili has been observed in electron micrographs of ' $\mathrm{Ca}$. L. asiaticus'; however, surface appendages were observed in micrographs of ' $\mathrm{Ca}$. L. solanacearum' within infected potato psyllids (Cicero et al. 2016). By contrast, both flagella and pili were observed in micrographs of $L$. crescens, swimming and twitching motility were readily confirmed in culture, and knockout mutations of $L$. crescens flagellar genes $f l g K$ (B488_RS04530) and $f l g F$ (B488_RS00930) resulted in demonstrably reduced bacterial swimming motility (Cai et al. 2019).

Visibly marked bacterial strains can be useful for following movement and localization in host tissues. GFP-marked L. crescens has been used to demonstrate biofilm formation in microfluidic chambers and investigate environmental conditions that may be relevant to ' $\mathrm{Ca}$. L. asiaticus' biofilm regulation (Naranjo et al. 2019). Colonization of Malpighian tubules of the greater wax moth $G$. mellonella by GFP-marked L. crescens was demonstrated (Munoz-Bodnar et al. 2019), thereby providing a potential surrogate insect model host for $L$. crescens infection. This experimental model used in combination with microfluidic chambers may be useful for screening mutants and transformants affecting motility, secretion, and biofilm formation. The Galleria infection model may even prove useful in evaluating suspected ' $\mathrm{Ca}$. Liberibacter' effectors cloned, expressed, and secreted from L. crescens that are suspected of involvement in psyllid endosymbiosis and pathogen transmission.

L. crescens has also been used to characterize a few key genetic differences that likely determine both lack of culturability and pathogenicity of ' $C a$. Liberibacter' spp. Knockout mutations of the L. crescens sugar transporter gene sut (B488_RS00965) combined with expression analysis of the ' $\mathrm{Ca}$. L. asiaticus' ATP/ADP translocase gene $n t t A$ (CLIBASIA_RS01005) in L. crescens were used by Jain et al. (2017b) to confirm the proposed hypothesis (Hartung et al. 2011) that ' $\mathrm{Ca}$. L. asiaticus' is an intracellular energy scavenger in both plant and psyllid hosts (as ' $\mathrm{Ca}$. L. asiaticus' lacks a sut ortholog and L. crescens lacks a $n t t A$ translocase). As opposed to the cultured $L$. crescens, in addition to a truncated glycolytic pathway, all of the pathogenic ' $\mathrm{Ca}$. Liberibacter' spp. have also lost glyoxalase I (lactoylglutathione lyase; EC 4.4.1.5), the key enzyme required for detoxification of methylglyoxal, a cytotoxic byproduct of glycolysis (Jain et al. 2017b). Finally, characterization of L. crescens lipid A structure has proven quite useful in comparing and predicting differences from lipid A of pathogenic ' $\mathrm{Ca}$. Liberibacters' spp. As previously mentioned, all pathogenic and uncultured ' $C a$. Liberibacter' spp. lack LpxL, whereas the predicted L. crescens lpxL (B488_RS04675) encoded enzyme is homologous to the $S$. meliloti LpxXL catalyzing the very long chain fatty acid 

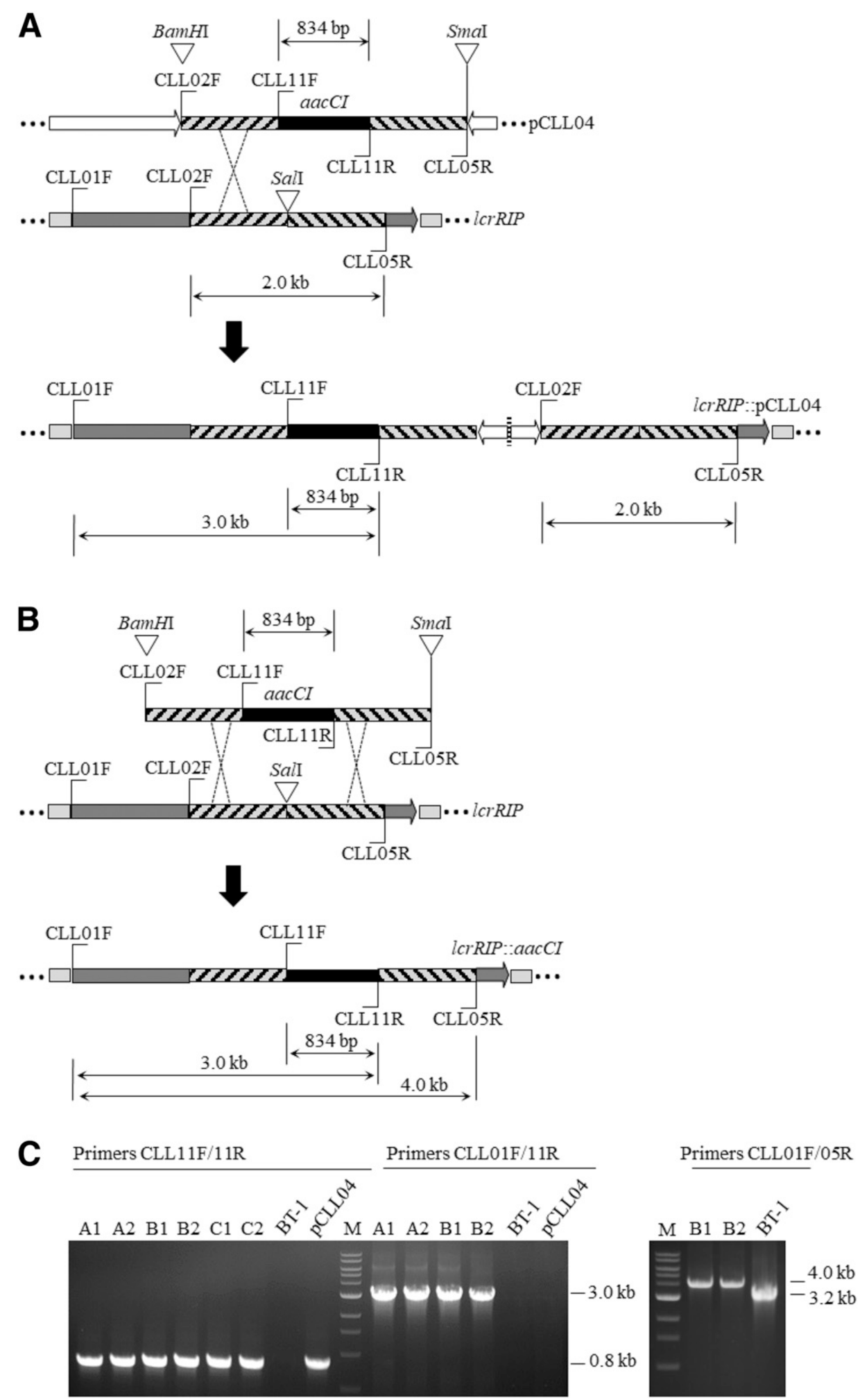

Fig. 4. A, Schematic design for construction of plasmid pCLL04 for marker interruption and marker exchange of the target locus lcrRIP in Liberibacter crescens BT-1 cells using a gentamycin acetyltransferase $(a a c C l)$ gene. A single homologous recombination event results in marker interruption, characterized by the duplication of the cloned homology region (hashed gray boxes) and integration of suicide vector pCLL04 (empty white box) in between two incomplete copies of the target locus in L. crescens BT-1 cells (lcrRIP::pCLL04). B, Double homologous recombination resulting in marker exchange, characterized by the insertion of the BamHI/SmaI released linear 2.834-kb fragment carrying aacC1 (filled black box) into the target locus in L. crescens BT-1 cells (lcrRIP::aacCI). C, Agarose gel $(0.8 \%)$ electrophoresis showing indicated PCR products obtained using primer pairs CLL11F/11R, CLL01F/11R, and CLL01F/05R for amplification of aacCI and the marker-interrupted target locus, respectively. Directional positions of different primers and sizes of the PCR-amplified products are indicated in A and B. Lanes: $\mathrm{M}=1-\mathrm{kb}$ ladder, A1 and A2 $=$ L. crescens $\mathrm{BT}-1$ cells transformed with pCLL04 via marker interruption (lcrRIP::pCLL04), B1 and B2 $=$ L. crescens BT-1 cells transformed via marker exchange (lcrRIP::aacCI), and C1 and C2 $=$ L. crescens $\mathrm{BT}-1$ cells transformed with pUFR071 (BT-1/pUFR071). 
(VLCFA) modification of lipid A. VLCFA-modified lipid A is a unique feature of several bacteria such as S. meliloti and Brucella abortus that form chronic intracellular infections within legumes and mammalian hosts (Ferguson et al. 2004). L. crescens lipid A has a penta-acylated chitobiose backbone, containing two ester-linked C16:0 (3-OH) and two amide-linked C14:0 (3-OH) fatty acid residues and a C28:0 (26-OH) VLCFA (Jain et al. 2019a). Although knockout mutations of various $L$. crescens genes are readily obtained (Cai et al. 2019; Jain et al. 2017b; Naranjo et al. 2019), mutations in the L. crescens lpxL gene appeared to be lethal, raising the speculation that uncultured ' $C a$. Liberibacter' spp. may require VLCFA-modified lipid A for free-living growth in culture.

L. crescens was naturally competent for direct uptake and chromosomal integration of both linear and circular plasmid DNA. Natural DNA transformation is a horizontal gene transfer mechanism for bacterial uptake of DNA through the base of T4P, followed by its stable integration in the recipient genome (Johnsborg et al. 2007; Mell and Redfield 2014). Natural transformation drives bacterial genome plasticity and adaptability and has been demonstrated in several bacterial species such as Streptococcus pneumoniae, Helicobacter pylori, X. fastidiosa, V. cholerae, E. coli, Agrobacterium tumefaciens, and Pseudomonas fluorescens. The 'Ca. Liberibacter' genomes are predicted to possess all of the structural genes required for assembly of T4P (Andrade and Wang 2019) and ultrastructural evidence for T4P has been documented in L. crescens (Cai et al. 2019) and 'Ca. L. solanacearum' (Cicero et al. 2016). T4P-mediated natural uptake of DNA by L. crescens appeared dependent on the presence of xanthan gum or chitin with the DNA. Chitin has been shown to be essential for natural transformation of $V$. cholerae (Udden et al. 2008).

Unlike Neisseria spp. that synthesize their competence proteins in a constitutive manner, it is likely that most naturally transformable bacteria regulate competence gene expression in response to certain cellular and/or environmental signals (Johnsborg et al. 2007). Natural competence for environmental DNA uptake likely fulfills a requirement of some bacteria for nutrients (i.e., the DNA is used as food, both nucleotides and phosphate), but for other bacteria, the competence involves both uptake for food and transformation for the acquisition of novel genetic material for repair or adaptation. The confirmation of natural competence in L. crescens for transformation is also significant for the context of food and is consistent with previously reported lack of enzyme systems for purine and pyrimidine metabolism in the genomes of ' $\mathrm{Ca}$. Liberibacter' spp. (Hartung et al. 2011). Uptake of environmental DNA likely fulfills the nucleotide requirements, highlighting the need for adding nucleotides to overcome nutritional bottlenecks for successful culturing of ' $\mathrm{Ca}$. Liberibacter' spp. in axenic media. ' $C a$. L. asiaticus' appears to lack full-length versions of ComF, DprA, and ComEC, which are needed for the import and protection of intact DNA for transformation but are not essential for the import of DNA for food (Hovland et al. 2017; Seitz and Blokesch 2014).

' $C a$. L. asiaticus' has been transiently cocultured to maximum titers of $\sim 20,000$ cells/ml (Merfa and De La Fuente 2019). Such low-titer cultures are inadequate for typical transformation and electroporation methods and ' $\mathrm{Ca}$. L. asiaticus' may not be amenable to natural transformation owing to a lack of critical genes. Extracts of ' $C a$. L. asiaticus'-free psyllids were used to obtain plaque-like lytic zones on agar plated lawns of $L$. crescens expressing the ' $C a$. L. asiaticus' Outer Membrane Protein (ompA) gene (CLIBASIA_ RS00965; Sena-Velez et al. 2018), thus providing a possibility of phage transduction of ' $\mathrm{Ca}$. L. asiaticus' at low titer levels. Isolating bacteriophages able to infect ' $\mathrm{Ca}$. L. asiaticus' may provide novel molecular tools to genetically modify even transient and low-titer ' $C a$. L. asiaticus' to allow axenic cultures, as well as open avenues for reintroduction of ' $\mathrm{Ca}$. L. asiaticus' to plants and psyllids to explore more effective HLB control.

In the absence of culturable pathogenic Liberibacters (for a recent comprehensive review of culturing attempts, refer to Merfa et al.
2019), L. crescens has been developed into a genetically tractable proxy for the 'Ca. Liberibacter' spp. L. crescens has been transformed by replicative and integrative vectors carrying multiple ' $C a$. L. asiaticus' genes, and it has served as a gene expression and secretion host to characterize potential secreted effectors and even to approximate the lipopolysaccharide of the pathogenic ' $\mathrm{Ca}$. Liberibacter' spp. The ability to genetically transform $L$. crescens and infect a model insect host may make it easier to turn $L$. crescens into a cultured pathogen than to culture a pathogenic ' $\mathrm{Ca}$. Liberibacter' spp.

\section{ACKNOWLEDGMENTS}

We thank Patricia Rayside for excellent technical assistance.

\section{LITERATURE CITED}

Andrade, M. O., and Wang, N. 2019. The Tad pilus apparatus of Candidatus Liberibacter asiaticus and its regulation by VisNR. Mol. Plant-Microbe Interact. 10.1094/MPMI-02-19-0052-R

Bendtsen, J. D., Kiemer, L., Fausbøll, A., and Brunak, S. 2005. Non-classical protein secretion in bacteria. BMC Microbiol. 5:58.

Cai, L., Jain, M., Munoz-Bodnar, A., Fleites, L. A., Sena-Velez, M., Heck, M., and Jones, K. M., and Gabriel, D. W. 2019. Liberibacter crescens exhibits both flagellar swimming and type IV pili-mediated twitching motility in culture. Presented at the Sixth International Research Conference on Huanglongbing, Riverside, CA.

Castañeda, A., Reddy, J. D., El-Yacoubi, B., and Gabriel, D. W. 2005. Mutagenesis of all eight avr genes in Xanthomonas campestris pv. campestris had no detected effect on pathogenicity, but one $a v r$ gene affected race specificity. Mol. Plant-Microbe Interact. 18:1306-1317.

Cicero, J. M., Fisher, T. W., and Brown, J. K. 2016. Localization of 'Candidatus Liberibacter solanacearum' and evidence for surface appendages in the potato psyllid vector. Phytopathology 106:142-154.

Cong, Q., Kinch, L. N., Kim, B. H., and Grishin, N. V. 2012. Predictive sequence analysis of the Candidatus Liberibacter asiaticus proteome. PLoS One 7:e41071.

Coyle, J. F., Pagliai, F. A., Zhang, D., Lorca, G. L., and Gonzalez, C. F. 2018. Purification and partial characterization of LdtP, a cell envelope modifying enzyme in Liberibacter asiaticus. BMC Microbiol. 18:201.

Davis, M. J., Mondal, S. N., Chen, H. Q., Rogers, M. E., and Brlansky, R. H. 2008. Co-cultivation of 'Candidatus Liberibacter asiaticus' with Actinobacteria from citrus with huanglongbing. Plant Dis. 92:1547-1550.

De Feyter, R., and Gabriel, D. W. 1991. Use of cloned DNA methylase genes to increase the frequency of transfer of foreign genes into Xanthomonas campestris pv. malvacearum. J. Bacteriol. 173:6421-6427.

De Feyter, R., Kado, C. I., and Gabriel, D. W. 1990. Small, stable shuttle vectors for use in Xanthomonas. Gene 88:65-72.

De Feyter, R., Yang, Y., and Gabriel, D. W. 1993. Gene-for-gene interactions between cotton $R$ genes and Xanthomonas campestris pv. malvacearum avr genes. Mol. Plant-Microbe Interact. 6:225-237.

Duan, Y., Zhou, L., Hall, D. G., Li, W., Doddapaneni, H., Lin, H., Liu, L., Vahling, C. M., Gabriel, D. W., Williams, K. P., Dickerman, A., Sun, Y., and Gottwald, T. 2009. Complete genome sequence of citrus huanglongbing bacterium, 'Candidatus Liberibacter asiaticus' obtained through metagenomics. Mol. Plant-Microbe Interact. 22:1011-1020.

Emiola, A., George, J., and Andrews, S. S. 2015. A complete pathway model for lipid A biosynthesis in Escherichia coli. PLoS One 10:e0121216.

Fagen, J. R., Leonard, M. T., McCullough, C. M., Edirisinghe, J. N., Henry, C. S., Davis, M. J., and Triplett, E. W. 2014. Comparative genomics of cultured and uncultured strains suggests genes essential for free-living growth of Liberibacter. PLoS One 9:e84469.

Ferguson, G. P., Datta, A., Baumgartner, J., Roop, R. M., Carlson, R. W., and Walker, G. C. 2004. Similarity to peroxisomal-membrane protein family reveals that Sinorhizobium and Brucella BacA affect lipid-A fatty acids. Proc. Natl. Acad. Sci. USA 101:5012-5017.

Fleites, L. A., Jain, M., Zhang, S., and Gabriel, D. W. 2014. "Ca. Liberibacter asiaticus" prophage late genes may limit host range and culturability. Appl. Environ. Microbiol. 80:6023-6030.

Fujiwara, K., Iwanami, T., and Fujikawa, T. 2018. Alterations of Candidatus Liberibacter asiaticus-associated microbiota decrease survival of $\mathrm{Ca}$. L. asiaticus in in vitro assays. Front. Microbiol. 9:3089.

Gabriel, D. W., Gottwald, T. R., Lopes, S. A., and Wulff, N. A. 2019. Bacterial pathogens. In: The Genus Citrus, 1st ed. M. Talon, M. Caruso, and F. Gmitter, eds. Woodhead Publishing, Elsevier, London.

Grafton-Cardwell, E. E., Stelinski, L. L., and Stansly, P. A. 2013. Biology and management of Asian citrus psyllid, vector of the huanglongbing pathogens. Annu. Rev. Entomol. 58:413-432. 
Guilhabert, M. R., and Kirkpatrick, B. C. 2003. Transformation of Xylella fastidiosa with broad host range RSF1010 derivative plasmids. Mol. Plant Pathol. 4:279-285.

Hao, G., Boyle, M., Zhou, L., and Duan, Y. 2013. The intracellular citrus Huanglongbing bacterium, 'Candidatus Liberibacter asiaticus' encodes two novel autotransporters. PLoS One 8:e68921.

Hartung, J. S., Shao, J., and Kuykendall, L. D. 2011. Comparison of the ' $\mathrm{Ca}$. Liberibacter asiaticus' genome adapted for an intracellular lifestyle with other members of the Rhizobiales. PLoS One 6:e23289.

Hink, W. F. 1970. Established insect cell line from the cabbage looper, Trichoplusia ni. Nature 226:466-467.

Hovland, E., Beyene, G. T., Frye, S. A., Homberset, H., Balasingham, S. V., Gómez-Muñoz, M., Derrick, J. P., Tønjum, T., and Ambur, O. H. 2017. DprA from Neisseria meningitidis: Properties and role in natural competence for transformation. Microbiol. 163:1016-1029.

Jain, M., Black, I., Hawara, E., Azadi, P., Carlson, R., Ma, W., and Jones, K. M., and Gabriel, D. W. 2019a. Biochemical characterization of Liberibacter crescens lipopolysaccharide (LPS). Presented at the Sixth International Research Conference on Huanglongbing, Riverside, CA.

Jain, M., Fleites, L. A., and Gabriel, D. W. 2015. Prophage-encoded peroxidase in 'Candidatus Liberibacter asiaticus' is a secreted effector that suppresses plant defenses. Mol. Plant-Microbe Interact. 28:1330-1337.

Jain, M., Fleites, L. A., and Gabriel, D. W. 2017a. A small Wolbachia protein directly represses phage lytic cycle genes in "Candidatus Liberibacter asiaticus" within psyllids. MSphere 2:e00171-1.

Jain, M., Munoz-Bodnar, A., and Gabriel, D. W. 2017b. Concomitant loss of the glyoxalase system and glycolysis makes the uncultured pathogen "Candidatus Liberibacter asiaticus" an energy scavenger. Appl. Environ. Microbiol. 83:e01670-17.

Jain, M., Munoz-Bodnar, A., and Gabriel, D. W. 2019b. 'Candidatus Liberibacter asiaticus' peroxiredoxin (LasBCP) suppresses oxylipin-mediated defense signaling in citrus. J. Plant Physiol. 236:61-65.

Jain, M., Munoz-Bodnar, A., Zhang, S., and Gabriel, D. W. 2018. A secreted 'Candidatus Liberibacter asiaticus' peroxiredoxin simultaneously suppresses both localized and systemic innate immune responses in planta. Mol. Plant-Microbe Interact. 31:1312-1322.

Johnsborg, O., Eldholm, V., and Håvarstein, L. S. 2007. Natural genetic transformation: Prevalence, mechanisms and function. Res. Microbiol. 158: 767-778.

Kovach, M. E., Elzer, P. H., Hill, D. S., Robertson, G. T., Farris, M. A., and Roop, R. M. 1995. Four new derivatives of the broad host-range cloning vector pBBR1MCS, carrying different antibiotic-resistance cassettes. Gene 166:175-176.

Leonard, M. T., Fagen, J. R., Davis-Richardson, A. G., Davis, M. J., and Triplett, E. W. 2012. Complete genome sequence of Liberibacter crescens BT-1. Stand. Genomic Sci. 7:271-283.

Lin, H., Lou, B., Glynn, J. M., Doddapaneni, H., Civerolo, E. L., Chen, C., and Vahling, C. M. 2011. The complete genome sequence of 'Candidatus Liberibacter solanacearum', the bacterium associated with potato zebra chip disease. PLoS One 6:e19135.

Lin, H., Pietersen, G., Han, C., Read, D. A., Lou, B., Gupta, G., and Civerolo, E. L. 2015. Complete genome sequence of "Candidatus Liberibacter africanus," a bacterium associated with citrus huanglongbing. Genome Announc. 3:e00733-15.

Mell, J. C., and Redfield, R. J. 2014. Natural competence and the evolution of DNA uptake specificity. J. Bacteriol. 196:1471-1483.

Merfa, M. V., and De La Fuente, L. 2019. Optimization of grapefruit juice for culturing of 'Candidatus Liberibacter asiaticus'. Presented at the Sixth International Research Conference on Huanglongbing, Riverside, CA.

Merfa, M. V., Pérez-López, E., Naranjo, E., Jain, M., Gabriel, D. W., and De La Fuente, L. 2019. Progress and obstacles in culturing 'Candidatus
Liberibacter asiaticus', the bacterium associated with Huanglongbing (HLB). Phytopathology doi:10.1094/PHYTO-02-19-0051-RVW

Monger, W. A., and Jeffries, C. J. 2018. A survey of 'Candidatus Liberibacter solanacearum' in historical seed from collections of carrot and related Apiaceae species. Eur. J. Plant Pathol. 150:803-815.

Munoz-Bodnar, A., Cai, L., and Jain, M., and Gabriel, D. W. 2019. Galleria mellonella: A model host for Liberibacters. Presented at the Sixth International Research Conference on Huanglongbing, Riverside, CA

Munoz-Bodnar, A., Fleites, L. A., Jain, M., and Gabriel, D. W. 2018. LC2 and $\mathrm{LC} 1$ act as key regulators of bacteriophage SC1 in Liberibacter crescens. Phytopathology S1(suppl.): 130.

Nakabachi, A., Nikoh, N., Oshima, K., Inoue, H., Ohkuma, M., Hongoh, Y., Miyagishima, S. Y., Hattori, M., and Fukatsu, T. 2013. Horizontal gene acquisition of Liberibacter plant pathogens from a bacteriome-confined endosymbiont of their psyllid vector. PLoS One 8:e82612.

Naranjo, E., Merfa, M. V., Ferreira, V., Jain, M., Davis, M. J., Bahar, O., Gabriel, D. W., and De La Fuente, L. 2019. Liberibacter crescens biofilm formation in vitro: Establishment of a model system for pathogenic 'Candidatus Liberibacter spp.'. Sci. Rep. 9:5150.

Pagliai, F. A., Gardner, C. L., Bojilova, L., Sarnegrim, A., Tamayo, C., Potts, A. H., Teplitski, M., Folimonova, S. Y., Gonzalez, C. F., and Lorca, G. L. 2014. The transcriptional activator LdtR from 'Candidatus Liberibacter asiaticus' mediates osmotic stress tolerance. PLoS Pathog 10:e1004101.

Parker, J. K., Wisotsky, S. R., Johnson, E. G., Hijaz, F. M., Killiny, N., Hilf, M. E., and De La Fuente, L. 2014. Viability of 'Candidatus Liberibacter asiaticus' prolonged by addition of citrus juice to culture medium. Phytopathology 104:15-26.

Prasad, S., Xu, J., Zhang, Y., and Wang, N. 2016. SEC-translocon dependent extracytoplasmic proteins of Candidatus Liberibacter asiaticus. Front. Microbiol. 7:1989.

Reddy, J. D., Reddy, S. L., Hopkins, D. L., and Gabriel, D. W. 2007. TolC is required for pathogenicity of Xylella fastidiosa in Vitis vinifera grapevines. Mol. Plant-Microbe Interact. 20:403-410.

Seitz, P., and Blokesch, M. 2014. DNA transport across the outer and inner membranes of naturally transformable Vibrio cholerae is spatially but not temporally coupled. MBio 5:e01409-14.

Sena-Velez, M., Jain, M., Gabriel, D. W., and Jones, K. M. 2018. 'Candidatus Liberibacter asiaticus' bacteriophage search and the role of the OmpA protein in Liberibacter species. (Abstr.) Phytopathology 108:(Suppl. 1): S1.129.

Singh, A., Kumar, N., Tomar, P. P., Bose, S., Ghosh, D. K., Roy, P., and Sharma, A. K. 2017. Characterization of a bacterioferritin comigratory protein family 1-Cys peroxiredoxin from Candidatus Liberibacter asiaticus. Protoplasma 254:1675-1691.

Udden, S. N., Zahid, M. S. H., Biswas, K., Ahmad, Q. S., Cravioto, A., Nair, G. B., Mekalanos, J. J., and Faruque, S. M. 2008. Acquisition of classical CTX prophage from Vibrio cholerae $\mathrm{O} 141$ by El Tor strains aided by lytic phages and chitin-induced competence. Proc. Natl. Acad. Sci. USA 105: 11951-11956.

Wulff, N. A., Zhang, S., Setubal, J. C., Almeida, N. F., Martins, E. C., Harakava, R., Kumar, D., Rangel, L. T., Foissac, X., Bové, J. M., and Gabriel, D. W. 2014. The complete genome sequence of 'Candidatus Liberibacter americanus', associated with citrus Huanglongbing. Mol. Plant-Microbe Interact. 27:163-176.

Yan, Q., Sreedharan, A., Wei, S., Wang, J., Pelz-Stelinski, K., Folimonova, S., and Wang, N. 2013. Global gene expression changes in Candidatus Liberibacter asiaticus during the transmission in distinct hosts between plant and insect. Mol. Plant Pathol. 14:391-404.

Zhang, Y., Callaway, E. M., Jones, J. B., and Wilson, M. 2009. Visualisation of hrp gene expression in Xanthomonas euvesicatoria in the tomato phyllosphere. Eur. J. Plant Pathol. 124:379-390. 